\title{
CHIP REMOVAL SPECIALITIES IN MULTI-DIRECTIONAL TURNING
}

\author{
Viktor RÁCZI ${ }^{1}$, Sándor SIPOS ${ }^{2}$, Gabriella FARKAS ${ }^{3}$ \\ Óbuda University, Donát Bánki Faculty of Mechanical Engineering, Inst. of Materials and Manufacturing \\ Sciences, Budapest, Hungary \\ ${ }^{1}$ raczi.viktor@bgk.uni-obuda.hu \\ ${ }^{2}$ sipos.sandor@bgk.uni-obuda.hu \\ 3farkas.gabriella@bgk.uni-obuda.hu
}

\begin{abstract}
For machining of increasingly complicated geometries, the longitudinal and transverse turning operations should be performed with a single tool. Leading manufacturing companies have developed a number of constructions. The world's largest manufacturer has recently revolutionised turning by launching roughing and finishing tools. The roughing insert can work with "high feed turning" in four different directions of movement. This tool has a unique chip forming and removal, it forms a unique machined surface. This study gives an overview of the results achieved in this area.
\end{abstract}

Keywords: multi-directional turning, PrimeTurning, new turning movements.

\section{Introduction}

It is not easy to choose the appropriate tool for machining of even more complicated component geometries, it is an especially time-consuming task. In the case that a single tool is enough to carry out longitudinal and transverse turning operations of rotationally symmetric solids, then not only does the utilization of the CNC-lathes yield a decrease of setup time and downtime, but also there is a reduction in the number of necessary turning tools (i.e. tooling costs), and, furthermore, in the necessary tool change time, too.

Several constructions have been worked out for the tooling process of multi-directional turning (MDT) by leading tool manufacturing companies over the past few years (see ISO standard 1832). If the insert included angle is too great (EPSR $\geq 80^{\circ}$ ), then the turning operation can be carried out only in a longitudinal and/or transverse direction. If its value is between $35 \ldots 60^{\circ}$, then the contour can be machined, too. Also, the versions with inserts can be successfully applied, in this case, the tools look like grooving/parting off instruments, having a long and narrow "blade part", fixed in the tool holder with a "V" shaped clamping, with inserts on one or two tool grooving ends. With these, grooving and the subsequent longitudinal and even the contour turning operations can be carried out, too [1].

The world's leading tool manufacturer appeared on the market with two turning tools in mid-2017, with their new construction, working on new principles, they have almost revolutionised the whole process of turning [2].

The tools, working on new principles (Figure 1.), can be distinguished by the following features:

- the feed movement happens from chuck to the tailstock;

-in order to achieve the necessary cutting depth, a grooving movement is initially necessary; -the tool cutting edge angle is much smaller $\left(\mathrm{KAPR}=25 \ldots 30^{\circ}\right)$ than usually applied.

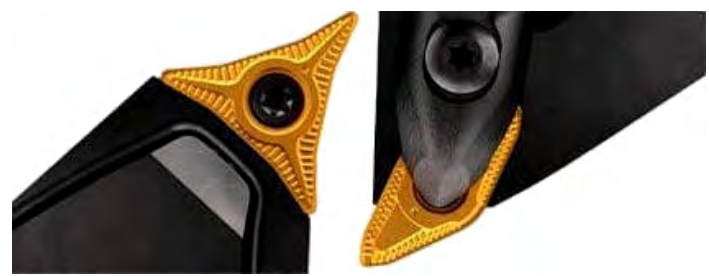

Figure 1. Two types of PrimeTurning ${ }^{\mathrm{TM}}$ tools: "A"-finishing, "B"-roughing 


\section{Cutting tests with B type PrimeTur- ning $^{\mathrm{TM}}$ tool}

The rough turning tests were carried out on a CNC-lathe, manufacturer: Dugard Eagle, model: BNC1840; the work piece was clamped in a chuck, supported by the tailstock. During the trials, no cooling-lubricating medium was applied.

For the tests, sample pieces were used, having a size of $\emptyset 60 \times 160 \mathrm{~mm}$, with a clamp bolt and tool runout on the chuck side and support from the tailstock through a centre hole. They were made of $11 \mathrm{SMn} 30+\mathrm{C}$ automata steel material, with a hardness of HB150 \pm 3 .

To the tests tool holder, type: CP-25BR-2525-11, and roughing insert, type: CP-B1108_M5 4325 (Figure 2.), were applied.

The cutting data were varied on 3 and 4 levels: the cutting speed $(\mathrm{vc})$ in the range of $\mathrm{vc}=160 \ldots$ $250 \mathrm{~m} / \mathrm{min}$, the depth of cut in the range of $\mathrm{a}=$ $0,5 \ldots 1,5 \mathrm{~mm}$, while the feed in the range of $\mathrm{f}=$ $0,3 \ldots 1,2 \mathrm{~mm}$ (this is the case of the partial factor analysis with the „slipped” feed values) [3].
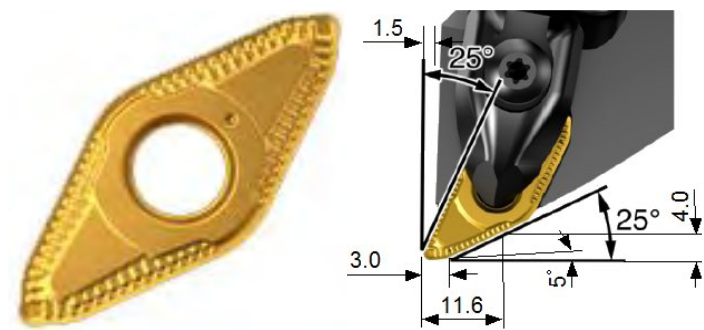

Figure 2. CP-B1108-M5 insert and roughing tool geometry

\subsection{Chip formation and force effects}

The turning tool, moving in the opposite direction than usual, and having a cutting edge angel (KAPR) of $25^{\circ}$, detaches much thinner and wider chips than the conventional tools. The feed values could even be doubled: the insert is able to work in a "high feed turning” mode, in four movement directions (when working in the conventional direction, it can carry out a finishing process). The „B” tool has a unique construction (cutting edge is formed by two sections, having different point angles, which connected a great radius), therefore its chip formation is unique (Figure 3.).

As can be easily seen, the divider elements, placed in the chip breaker, are copied on the chip. This characteristic feature has obviously an effect on the surface quality.

The chip chart, made based on the turning tests with ten different settings (Figure 4.), shows: there were favourably broken chips in eight cases, while in case of the highest cutting data there were developed dangerously coiled, tangled chips. The average force components, measured with KISTLER 9021A type equipment and evaluated with Dynoware software, confirm that the force effects can be well modelled with the functions

$$
F_{i}=C_{F i} \cdot a^{y_{F i}} \cdot f^{x_{F i}}[\mathrm{~N}]
$$

where the constant $C_{F i}$ and the exponents $\left(x_{F P} y_{F i}\right)$, belonging to the force components $F_{c}, F_{f}$ and $F_{p}$ calculated with two-factor-regression (see Figure 5.).

The feed force is small, it is only 10-20 percent of the cutting force. This ratio can be explained by the unusually small cutting edge angles, and it is a reason for the expressly greater value of passive force and for the significant ratio of $F_{p} / F_{c}$ in the range of $0,55 \ldots 0,76$, too.

The $F_{p}$ is a decisive factor in the development of machining accuracy. In the case of the highest cutting data, the measured barrel form error was $\Delta \mathrm{D}=52 \mu \mathrm{m}$, obviously, at the tailstock side.

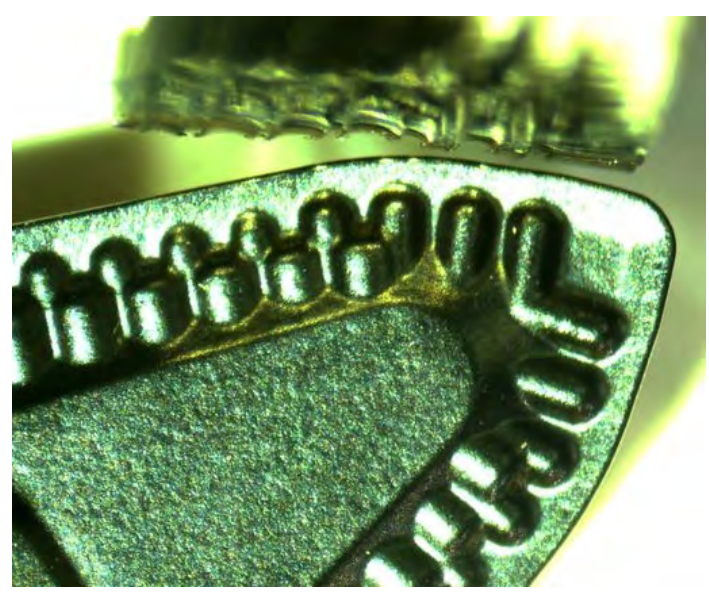

Figure 3. The „ $B$ ” insert and the chip. Conditions: $a=1,5 \mathrm{~mm} ; f=1,2 \mathrm{~mm}$

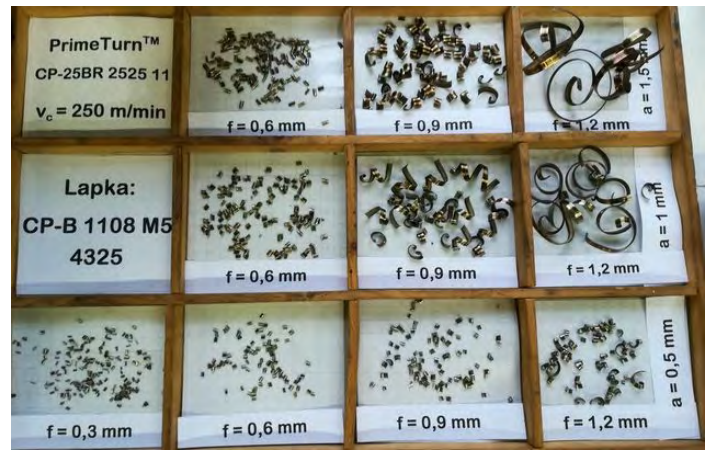

Figure 4. The chart of the detached chips 


\subsection{Surface quality}

In the present article, we are going to describe only some micro-geometrical characteristics of the machined surface [1].

The Wt waviness values (of filtered profile) of the surface, machined with „B” tool, are shown in Figure 6. It can be considered that waviness is on the increase mainly as a result of the depth of cut, while the feed value has its optimal level in case of setting $\mathrm{f}=0,9 \mathrm{~mm}$.

Although the surface roughness of the turned surface does not mean a serious requirement (usually $\mathrm{Rz} \leq 25 \mu \mathrm{m}$ ) in case of roughing operation, the development of roughness values, measured in case of our settings, is demonstrated in Figure 7.

It can be considered that due to the edge construction none of the formulas (for example, the Bauer-formula, mentioned in [1]) can be applied. The single-factor polynom in the following form

$$
R z=A \cdot f^{2}+B \cdot f+C \quad[\mu \mathrm{m}]
$$

is favourable to calculate both roughness and feed values [3].

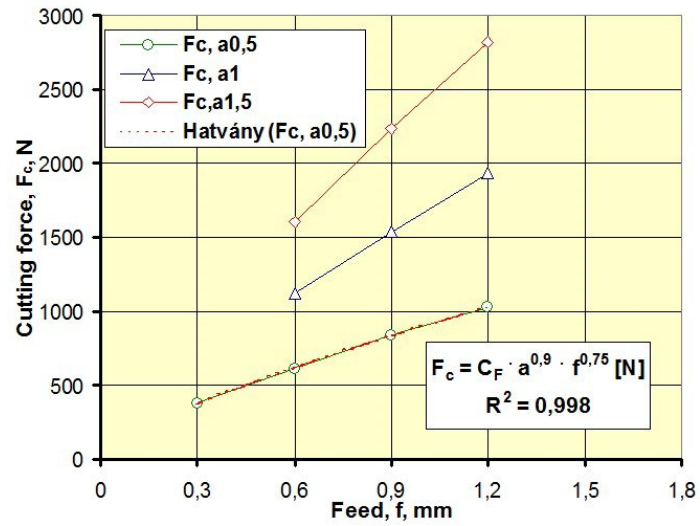

Figure 5. The development and model of the cutting force

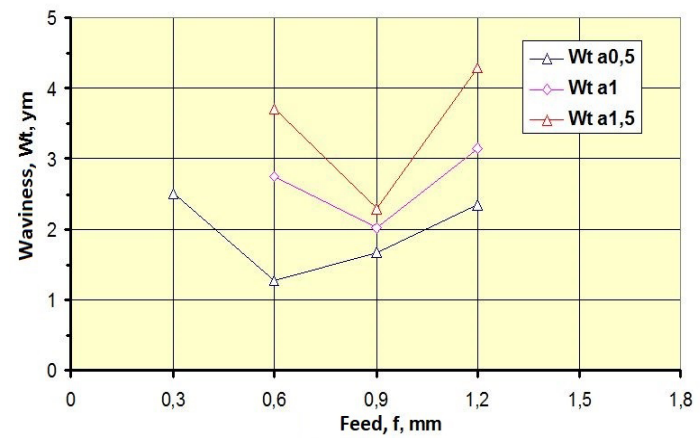

Figure 6. The development of the waviness
We note that smaller $\mathrm{Rz}$ values were always measured in the case of greater depth of cuts. This is explained by the prestress effect of increasing radial force to a workpiece-machine-tool system of the turning process, and, at the same time, it leads to axial form errors and increased waviness of the machined surface. Due to this reason only robust, stiff workpieces can be turned with "B" tools, having small KAPR angles.

\subsection{Productivity}

The increased feed values mean a more intensive (even up to $450 \mathrm{~cm} 3 / \mathrm{min}$ ) material removal, the machine main time is on the decrease, as a result of it, the productivity (piece/hour) is on the increase. If there are developed favourable broken chips, then cutting speed - taking the performance limits of the machine into consideration - can be increased and it can raise the machine utilisation even more.

This type of tool can be used with reverse feed and rotation, and conventional feeds (i. e. in finishing mode) even to contour turning of workpieces with small taperness (Figure 8.).

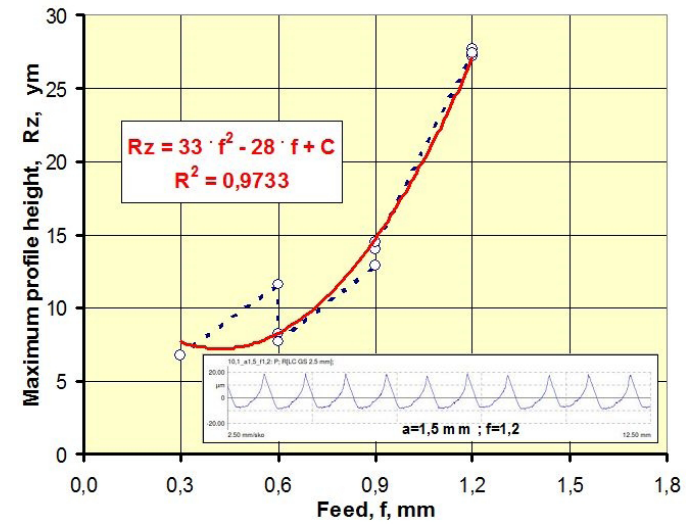

Figure 7. The development and model of maxi-mum profile height

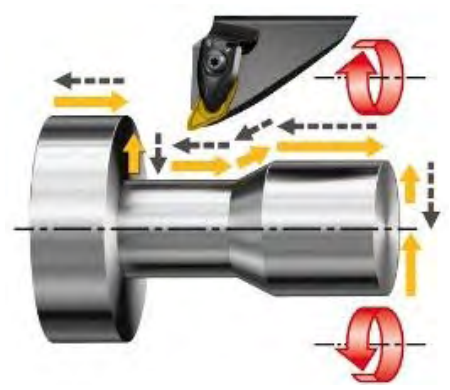

Figure 8. The movement directions of „B” tool (continuous line: roughing, broken line: finishing) 


\section{Summary, further tasks}

The cutting tests have demonstrated that the tool can be effectively applied to roughing tasks: this instrument, having a smaller cutting edge angle than usual, is appropriately stable, the chip detachment is reliable, the surface finish producing capability of the insert is favourable, too. The consequences of the elastic deformation, caused by passive force, were the size deviations on the samples and the surface roughness; they fell in the usual ranges of roughing accuracy. The "B" tool can be used only for stiff workpieces.

During the tests, there was no perceived wear on the insert as the developed mechanical and thermal load distributed well along the tool edge. In the case of the given task, the increased cutting speed, the raised (sometimes to double) feed rate and code generator of some CAM systems are compensated by the relatively small depth of cut value.

Our further work will include tests, to be carried out on different steels (including hard-tomachine, corrosion resistant grades) in order to explore the limits of certain settings and to examine the efficiency of use of the tool, shown in Figure 1. and developed to finishing tasks.

\section{References}

[1] Sipos S., Palásti-Kovács B., Horváth R.: Forgácsolótechnológiák és szerszámai. ÓE BGK3057, Budapest, 2015. 111-158.

[2] SandvikCoromant_PrimeTurning-SCREEN_150_ PPI, 2016.

[3] Iscar gyártmányú esztergalapkák komplex vizsgálata és minősítése. Kutatási jelentés, ÓE/BGK/ AGI-GIT, Budapest, 2017. pp. 57 